\title{
Assessment of knowledge, attitude and practice towards tuberculosis infection control among health professionals in Nekemte Referral Hospital, Nekemte, Oromia, West Ethiopia: cross sectional facility-based study.
}

\author{
Eba Abdisa Golja \\ Wollega University, Institute of Health Sciences, School of Nursing and Midwifery
}

\begin{abstract}
Poor knowledge, poor practice and poor attitude among health care workers may lead to the increased risk of nosocomial tuberculosis transmission. This study was aimed to assess knowledge, attitudes and practice of health professionals towards tuberculosis infection control in Nekemte Referral Hospital, Nekemte, west Ethiopia.
\end{abstract}

An institutional based cross-sectional study design was conducted in September and October 2019 among 223 health professionals in Nekemte Referral Hospital. Data were collected by using self-administered structured questionnaires which had subdivided components, and analysis was done by double entry of SPSS version 21.

Two hundred study participants responded to our current study with a response rate of $89.6 \%$. In this study, majority of respondents, $54 \%$, were females and $55 \%$ of them are first degree holders. From all respondents, $14(7 \%), 43$ (21.5\%), and 60 (30\%) had poor knowledge, poor attitudes towards and poor practice towards tuberculosis infection control, respectively.

This study found that significantly high proportion of HCWs had good knowledge, attitude and practice towards tuberculosis infection control.

Keywords: knowledge, attitudes, practice; healthcare workers; tuberculosis; prevention; Ethiopia

\section{Corresponding author:}

Eba Abdisa Golja,

Wollega University, Institute of Health Sciences, School of Nursing and Midwifery

EMAIL: ebajije1355@gmail.com 


\section{Introduction}

Tuberculosis (TB) is an infection caused by the bacillus Mycobacterium tuberculosis, which affects lungs, and causes extra pulmonary TB, which affects other body parts. When the patient discharges bacilli to the air through coughing and sneezing, it can be easily spread to other people. In this case, people living in the same household, and having frequent contact with an infectious patient have the greatest risk of contracting TB. ${ }^{1}$

According to World Health Organization in 2017, there were an estimated 10.4 million new TB case. Ethiopia is one of the countries affected by disease, ranked seventh in the world and third in Africa. ${ }^{2}$ One study identified that in 2016, new TB cases numbered 219,186 , with prevalence of 151,602 cases and 48,910 deaths. ${ }^{3}$ Another study found that the number of patients following Nekemte Referral Hospital was very high. ${ }^{4}$ In a prison which is located to next Nekemte Referral Hospital, the prevalence of latent TB infection was also $51.2 \%{ }^{5}$

Tuberculosis infection control is a subcomponent of the WHO updated Stop TB Strategy contributing to strengthening of health systems. It is one of the three activities to reduce the burden of TB in persons living with HIV/AIDS. ${ }^{6}$ It is recommended that all health-care settings should have a TB infection-control program. ${ }^{7}$ Healthcare workers, especially those who had frequent contacts with TB patients, are at higher risk of TB infection compared to the general population. The incidence of TB among people working in congregate settings like laboratories, TB clinics and wards exceeds that of the general population. ${ }^{8}$ Tuberculosis is highly transmissible in resourcelimited healthcare facilities in which HCWs are at great risk of acquiring TB. ${ }^{9}$ Several studies have confirmed that TB is a significant occupational risk among HCWs in low-and middle income countries, ${ }^{10}$ and it is estimated that the incidence of TB among HCWs in high burden countries ( $>100$ cases $/ 100,000$ population) is $8.4 \%$ greater $(95 \% \mathrm{Cl} 2 \cdot 7 \%-14.0 \%)$ than the general population. ${ }^{11}$

The highest prevalence of TB was found among laboratory staff (43.4\%), followed by technician staff
(39.4\%), doctors (34.4\%) and nurses (32.2\%), and the lowest was observed in administrative staff (25.2\%) in China. ${ }^{12}$ In Ethiopia, better HCW knowledge and positive attitude are more common among those who received training and orientation towards $T B$ infection control. Use of face mask among the HCWs was limited. ${ }^{13}$ In Ethiopia, the safe infection prevention practice significantly increased if $\mathrm{HCW}$ s had received training and had infection prevention guidelines available at their work. ${ }^{14}$ Another study done in Addis Ababa indicated that one third of HCWs had poor knowledge and half of them had poor practice towards TB infection prevention, and the level of infection prevention was significantly associated with year of experiences, having TB related training. ${ }^{15}$

Thus, in this study, an attempt was made to assess the knowledge, attitude and practice of infection control among HCWs in Nekemte Referral Hospital, Ethiopia.

\section{Methods}

\section{Study area and period}

The study was conducted at Nekemte town from September 2019 to October 2019. This town is found in Oromia region, western Ethiopia; it is $331 \mathrm{~km}$ away from Addis Ababa, the capital city of Ethiopia, and currently serves as a capital city of East Wollega zone. This hospital is giving service for about more than 2 million population. This hospital has been serving the population with four big wards and more than ten outpatient departments. It has 18 specialists, 20 general practitioners, 130 nurses, 18 laboratory technicians, 16 pharmacists and more than 250 administrative staff. Currently, more than 3000 TB patients have been following their treatment according to the Administrative office data.

\section{Aim of the study}

The main aim of the study was to assess knowledge, attitude and practice toward TB infection control among HCWs of Nekemte Referral Hospital, Nekemte, Oromia, West Ethiopia, 2019.

\section{Study design}

An institutional based cross-sectional study design was carried out. 


\section{Study population}

All health professionals who were currently working in Nekemte referral hospital including doctors, nurses, midwifes, pharmacy and laboratory personals were the study population. Some of them are currently working in the TB clinic, Others are also having the chance of getting TB patients at their serving units. For example, the clinicians working in obstetrics and gynecology wards have the chance to be infected from the women admitted for delivery or gynecology cases. In other non-specialized staff, they have the chance to rotate to TB clinic. That was why all health professionals were included.

\section{Sample size determination}

The total number of health professionals of this hospital is 223. Because of the small study population, we tried to include all health professionals in this study. Therefore, our study sample was 223.

\section{Data collection tools}

A semi structured questionnaires was used which was taken from similar studies ${ }^{16-18}$ for data collection; it has specific components of TB infection control questions, using the Program and Clinical Management of Tuberculosis Guideline of the Federal Ministry of Health (FMOH) in Ethiopia, ${ }^{19}$ and the World Health Organization policy on TB infection control in health care facilities with specific activities and evidencebased recommendations between 2009-2019. ${ }^{20}$ The tool comprised of HCWs' demographic and servicerelated variables (age, sex, education, job category, duration of employment, training/orientation on TB and TB infection control).

Knowledge was assessed using 11 questions by scoring the response 0 (zero) for wrong answers and 1 (one) for correct answers, and summing the scores. After checking the distribution of the responses, the midpoint was used as cut-off points for categorizing knowledge score as good (those who scored above 5.5) or poor (those who scored below 5.5).

There was a total of 12 questions to measure attitude using a scale ranging from strongly agree to strongly disagree. The scores were divided into two as positive attitude for those who scored above six and negative attitude for those who scored less than six.
Practice was assessed using eleven 11 statements with sub sections such as TB guidelines, ventilation of working area, patient education about TB and availability and use of personal protective equipment. Based on the midpoint, classification was made as good practice for those who scored greater than 5.5 or poor practice for those who scored less than 5.5.

\section{Data collection procedure}

Data were collected from volunteer health professionals self-report by using self-administered questionnaires after obtaining informed consent from the participants. The data collection tool was prepared in English considering that all health professionals were above certificate level of education. The questionnaires were distributed and collected by data collectors.

\section{Data quality assurance}

Quality of data collection process was supervised and monitored by supervisors and principal investigators. We did our research investigation among all health professionals by giving emphasis on ethical consideration. Prior to data collection, adequate training was given for data collectors and supervisors so that appropriate supervision was made. The questionnaire was prepared and customized to avoid entry of illegal values and skip patterns. Each questionnaire was given an identification number and validated by double entry of SPSS Version 21 (IBM, Armonk NY).

\section{Data management and analysis}

The collected data were checked for completeness, inconsistencies, and then data were coded, entered and cleaned using SPSS Version 21 by double entry. The results were presented using figures, tables and statements.

\section{Ethical considerations}

Permission to carry out this study was given from Institution Review Board (IRB) and Research Committee of the Institute of Health Sciences. Written consent was obtained from the respondents for their willingness to participate in this study. 
Table I. Sociodemographic characteristics of the 200 study participants, West Ethiopia, 2019

Characteristic

\begin{tabular}{|c|c|c|}
\hline \multirow[t]{4}{*}{ Age category } & $20-29$ & $60(30)$ \\
\hline & $30-39$ & $84(42)$ \\
\hline & $40-49$ & $41(20.5)$ \\
\hline & $50-59$ & $15(7.5)$ \\
\hline \multirow[t]{2}{*}{ Sex } & Male & 92 (46) \\
\hline & Female & $108(54)$ \\
\hline \multirow[t]{3}{*}{ Marital status } & Married & $144(72)$ \\
\hline & Single & $54(27)$ \\
\hline & Divorced or widowed & $2(1)$ \\
\hline \multirow[t]{6}{*}{ Profession } & Nurse & 99 (49.5) \\
\hline & Physician & $35(17.5)$ \\
\hline & Midwifery & $31(15.5)$ \\
\hline & Pharmacy personnel & $20(10)$ \\
\hline & Laboratory personnel & $14(7)$ \\
\hline & Health officer & $1(0.5)$ \\
\hline \multirow[t]{9}{*}{ Current working unit } & Outpatient department & $55(27.5)$ \\
\hline & Gynecology and obstetrics & $41(20.5)$ \\
\hline & Medical ward & $28(14)$ \\
\hline & Surgical ward & $26(13)$ \\
\hline & Pharmacy & $19(9.5)$ \\
\hline & Laboratory & $14(7)$ \\
\hline & Pediatrics & $13(6.5)$ \\
\hline & TB clinic or TB ward & $3(1.5)$ \\
\hline & Triage & $1(0.5)$ \\
\hline \multirow[t]{3}{*}{ Education } & Diploma & $53(26.5)$ \\
\hline & First degree & $110(55)$ \\
\hline & Second degree and above & 37 (18.5) \\
\hline \multirow[t]{3}{*}{ Service years in health facility } & $<3$ & $51(25.5)$ \\
\hline & $3-6$ & $67(33.5)$ \\
\hline & $>6$ & $82(41.5)$ \\
\hline \multirow[t]{2}{*}{ Experience in TB clinics } & Yes & $89(44.5)$ \\
\hline & No & $111(55.5)$ \\
\hline \multirow[t]{3}{*}{ If yes, how many years } & $<1$ & $41(46)$ \\
\hline & $1-4$ & $24(27)$ \\
\hline & $>4$ & $24(27)$ \\
\hline \multirow[t]{2}{*}{ Receipt of TB training } & Yes & $89(44.5)$ \\
\hline & No & $111(55.5)$ \\
\hline \multirow[t]{4}{*}{ If yes, duration of training } & $<3$ days & $9(10.1)$ \\
\hline & 4-6 days & $26(29.2)$ \\
\hline & $7-10$ days & $33(37.1)$ \\
\hline & $>10$ days & $21(23.6)$ \\
\hline
\end{tabular}




\section{Results}

\section{Socio-demographic characteristics}

From 223 health professionals working in Nekemte Referral Hospital, 200 responded to our study, with response rate of $89.6 \%$. Most respondents, 108 (54\%), were females. The mean age of the respondents was 39.5 years with a range of 20 years to 59 years. Concerning educational status, more than half of the participants (55\%) have first degree. Professionally, nearly half of the respondents $(99,49.5 \%)$ were nurses. The majority of the study participants (82, 41\%) had greater than six years working experience in the health facility. Eighty-nine (44.50\%) had taken in TB related training. The socio demographics characters are depicted in Table I.
Facility and administration related characteristics of healthcare workers towards TB infection control As it is indicated in the Table II below, sixty percent of the respondents' work places were where windows were cross ventilated and $78 \%$ of study participants' work place rooms had TB treatment guidelines. The majority $(90.5 \%)$ of the respondents open their rooms while they are with TB patients.

\section{Knowledge of health professionals towards TB infection control}

The majority $(172,86 \%)$ of the respondents knew that "Regular screening of HCWs for TB is one of the TB infection control measures" whereas 110 (55\%) knew that surgical masks cannot protect the HCW from

Table II. Facility and administration related questions related to TB infection prevention control, West Ethiopia, 2019.

No. Facility and administration related questions for TB infection prevention

\begin{tabular}{|c|c|c|c|}
\hline \multirow[t]{2}{*}{1} & \multirow[t]{2}{*}{ Are the windows of your work place cross ventilated? } & No & $80(40 \%)$ \\
\hline & & Yes & $120(60 \%)$ \\
\hline \multirow[t]{2}{*}{2} & \multirow[t]{2}{*}{ Is there surgical mask available for TB suspected patients? } & No & $90(45 \%)$ \\
\hline & & Yes & $110(55 \%)$ \\
\hline \multirow[t]{2}{*}{3} & \multirow[t]{2}{*}{ Is there N95 mask available for health care workers? } & No & $82(41 \%)$ \\
\hline & & Yes & $118(59 \%)$ \\
\hline \multirow[t]{2}{*}{4} & \multirow[t]{2}{*}{ Is there TB treatment guidelines available? } & No & $44(22 \%)$ \\
\hline & & Yes & $156(78 \%)$ \\
\hline \multirow[t]{2}{*}{5} & \multirow[t]{2}{*}{ Is there TB prevention poster posted? } & No & $84(42 \%)$ \\
\hline & & Yes & $116(58 \%)$ \\
\hline \multirow[t]{2}{*}{6} & \multirow[t]{2}{*}{ Do you open the window when you are with TB patients? } & No & $19(9.5 \%)$ \\
\hline & & Yes & $181(90.5 \%)$ \\
\hline \multirow[t]{2}{*}{7} & \multirow[t]{2}{*}{ Is there face mask available for TB patients? } & No & $84(42 \%)$ \\
\hline & & Yes & $116(58 \%)$ \\
\hline \multirow[t]{2}{*}{8} & \multirow{2}{*}{$\begin{array}{l}\text { Do you wear face mask when you approach TB suspected } \\
\text { patients? }\end{array}$} & No & $68(34 \%)$ \\
\hline & & Yes & $132(66 \%)$ \\
\hline \multirow[t]{2}{*}{9} & \multirow[t]{2}{*}{ Do hospitals have appropriate color coded waste bins (disposals)? } & No & $41(20.5 \%)$ \\
\hline & & Yes & $159(79.5 \%)$ \\
\hline \multirow[t]{2}{*}{10} & \multirow{2}{*}{$\begin{array}{l}\text { Is there separated waiting area for TB suspected patients in your } \\
\text { Hospitals? }\end{array}$} & No & $103(51.5 \%)$ \\
\hline & & Yes & $97(48.5 \%)$ \\
\hline
\end{tabular}


inhaling M. tuberculosis containing aerosols. From 200 participants, 14 (7\%) had poor knowledge scores as indicated in Table III.

\section{Attitude of health professionals towards TB infection control}

The majority (157, 78.5\%) of HCWs had positive attitudes towards TB infection control. As shown in Table IV, the majority $(184,92 \%)$ of HCWs agreed that there is a need for a TB infection control guideline in health facilities. More than 75\% (159, 79.5\%) agreed that they should wear respirators while caring for TB patients. More than half $(116,58 \%)$ were concerned about being infected with TB and 87 (43.5\%) agreed that cough hygiene alone has no role in TB infection control.

\section{Practice of health professionals toward TB infection control}

The range of respondents' practice scores ranged from 1-11. As shown in Table V, 169 (84.5\%) of HCWs were opening the window whenever TB suspected or a confirmed patient is in the room. Most (161, 80.5\%) had always followed TB treatment guidelines to manage new-smear positive cases while 34 (17\%) of them used these sometimes, and 5 (2.5\%) never followed the guideline.

Table III. Knowledge of HCWs towards TB infection, West Ethiopia, 2019

\begin{tabular}{|c|c|c|c|}
\hline No. & Knowledge item & Response & $\mathrm{N}(\%)$ \\
\hline \multirow[t]{2}{*}{1.} & \multirow[t]{2}{*}{ The door and window of the room should left open } & No & $73(36.18 \%)$ \\
\hline & & Yes & $127(63.82 \%)$ \\
\hline \multirow[t]{2}{*}{2} & \multirow[t]{2}{*}{ HCW should minimize time for TB patient spend in HF } & No & $47(23.5 \%)$ \\
\hline & & Yes & $153(76.5 \% 0$ \\
\hline \multirow[t]{2}{*}{3} & \multirow[t]{2}{*}{ Surgical mask cannot protect the HCW from TB } & No & $90(45 \%)$ \\
\hline & & Yes & $110(55 \%)$ \\
\hline \multirow[t]{2}{*}{4} & \multirow[t]{2}{*}{ Respirator N95 can protect HW from TB } & No & $60(30 \%)$ \\
\hline & & Yes & $140(70 \%)$ \\
\hline \multirow[t]{2}{*}{5} & \multirow{2}{*}{$\begin{array}{l}\text { TB pts should be educated how to cover their mouth with a } \\
\text { handkerchief }\end{array}$} & No & $39(19.5 \%)$ \\
\hline & & Yes & $161(80.5 \%)$ \\
\hline \multirow[t]{2}{*}{6} & \multirow[t]{2}{*}{ Every facility should establish an Infection Control Committee } & No & $28(14 \%)$ \\
\hline & & Yes & $172(86 \%)$ \\
\hline \multirow[t]{2}{*}{7} & \multirow[t]{2}{*}{ TB suspected patients should get priority } & No & $66(33 \%)$ \\
\hline & & Yes & $134(67 \%)$ \\
\hline \multirow[t]{2}{*}{8} & \multirow{2}{*}{$\begin{array}{l}\text { Regular screening of HW for TB is one of the TB infection control } \\
\text { measures }\end{array}$} & No & $28(14 \%)$ \\
\hline & & Yes & $172(86 \%)$ \\
\hline \multirow[t]{2}{*}{9} & \multirow[t]{2}{*}{ Fans and towels can be used to reduce TB transmission in TB ward } & No & $58(29 \%)$ \\
\hline & & Yes & $142(71 \%)$ \\
\hline \multirow[t]{2}{*}{10} & \multirow[t]{2}{*}{ TB cannot transmitted from person to person by blood contact } & No & 39 (19.5\%) \\
\hline & & Yes & $161(80.5 \%)$ \\
\hline \multirow[t]{4}{*}{11} & \multirow{2}{*}{$\begin{array}{l}\text { Sputum microscopy is the most effective tools for the diagnosis } \\
\text { of TB }\end{array}$} & No & $62(31 \%)$ \\
\hline & & Yes & $138(69 \%)$ \\
\hline & \multirow[t]{2}{*}{ Overall knowledge } & Good & $186(93 \%)$ \\
\hline & & Poor & $14(7 \%)$ \\
\hline
\end{tabular}

HCW: healthcare worker. 
Table IV. Attitude of HCWs towards TB infection control, West Ethiopia, 2019

\begin{tabular}{|c|c|c|c|}
\hline No. & Attitude statements & Response & $N(\%)$ \\
\hline \multirow[t]{3}{*}{1} & \multirow{3}{*}{$\begin{array}{l}\text { There is a need for guidelines regarding TB infection control in a } \\
\text { health care facility }\end{array}$} & Agree & $184(92 \%)$ \\
\hline & & Neutral & $13(6.5 \%)$ \\
\hline & & Disagree & $3(1.5 \%)$ \\
\hline \multirow[t]{3}{*}{2} & \multirow[t]{3}{*}{ HCWs should wear respirators while caring for TB patients } & Agree & $159(79.5 \%)$ \\
\hline & & Neutral & $31(15.5 \%)$ \\
\hline & & Disagree & $10(5 \%)$ \\
\hline \multirow[t]{3}{*}{3} & \multirow{3}{*}{$\begin{array}{l}\text { Respirators do not protect against drug-resistant TB even if I } \\
\text { wear it all time }\end{array}$} & Agree & $91(45.5 \%)$ \\
\hline & & Neutral & $29(14.5 \%)$ \\
\hline & & Disagree & $80(40 \%)$ \\
\hline \multirow[t]{3}{*}{4} & \multirow{3}{*}{$\begin{array}{l}\text { Even after a patient with TB leaves the room I am working in, I } \\
\text { remain at risk of contracting TB }\end{array}$} & Agree & $136(68 \%)$ \\
\hline & & Neutral & $18(9 \%)$ \\
\hline & & Disagree & $46(23 \%)$ \\
\hline \multirow[t]{3}{*}{5} & \multirow{3}{*}{$\begin{array}{l}\text { Most HCWs are already infected so there is no need of infection } \\
\text { control measures }\end{array}$} & Agree & $63(31.5 \%)$ \\
\hline & & Neutral & $25(12.5 \%)$ \\
\hline & & Disagree & $112(56 \%)$ \\
\hline \multirow[t]{3}{*}{6} & \multirow{3}{*}{$\begin{array}{l}\text { I do not wear respirator because patients do not like me to wear } \\
\text { it }\end{array}$} & Agree & $52(26 \%)$ \\
\hline & & Neutral & $29(14.5 \%)$ \\
\hline & & Disagree & $119(59.5 \%)$ \\
\hline \multirow[t]{3}{*}{7} & \multirow[t]{3}{*}{ I am concerned about being infected with TB } & Agree & $116(58 \%)$ \\
\hline & & Neutral & $25(12.5 \%)$ \\
\hline & & Disagree & $59(29.5 \%)$ \\
\hline \multirow[t]{3}{*}{8} & \multirow{3}{*}{$\begin{array}{l}\text { There is need to screen HCWs who may be exposed to TB for TB } \\
\text { infection or disease }\end{array}$} & Agree & $126(63 \%)$ \\
\hline & & Neutral & $43(21.5 \%)$ \\
\hline & & Disagree & $31(15.5 \%)$ \\
\hline \multirow[t]{3}{*}{9} & \multirow[t]{3}{*}{ I may turn off fans if they become noisy or cause cold air } & Agree & $104(52 \%)$ \\
\hline & & Neutral & $52(26 \%)$ \\
\hline & & Disagree & $44(22 \%)$ \\
\hline \multirow[t]{3}{*}{10} & \multirow{3}{*}{$\begin{array}{l}\text { Sputum induction procedures in wards put HCWs at an } \\
\text { increased risk of getting infected with TB }\end{array}$} & Agree & $144(72 \%)$ \\
\hline & & Neutral & $36(18 \%)$ \\
\hline & & Disagree & $20(10 \%)$ \\
\hline \multirow[t]{3}{*}{11} & \multirow[t]{3}{*}{ Cough hygiene has no role to play in infection control } & Agree & $87(43.5 \%)$ \\
\hline & & Neutral & $38(19 \%)$ \\
\hline & & Disagree & $75(37.5 \%)$ \\
\hline \multirow[t]{3}{*}{12} & \multirow{3}{*}{$\begin{array}{l}\text { HCWs working in HIV care and treatment clinics are at risk of } \\
\text { infection with TB }\end{array}$} & Agree & $137(68.84 \%)$ \\
\hline & & Neutral & $42(20.6 \%)$ \\
\hline & & Disagree & $21(10.55 \%)$ \\
\hline \multirow{2}{*}{\multicolumn{2}{|c|}{ Overall attitude }} & Good & $157(78.5 \%)$ \\
\hline & & Poor & $43(21.5 \%)$ \\
\hline
\end{tabular}

HCW: healthcare worker. 
Table V. Practice of HCW towards TB infection control, West Ethiopia, 2019

\begin{tabular}{|c|c|c|c|}
\hline No. & Practice Item & Response & $N(\%)$ \\
\hline \multirow[t]{3}{*}{1} & \multirow{3}{*}{$\begin{array}{l}\text { Facilities leaders monitor and evaluate HCWs on TB infection } \\
\text { control. }\end{array}$} & Always & $138(69 \%)$ \\
\hline & & Sometimes & $52(26 \%)$ \\
\hline & & Never & $10(5 \%)$ \\
\hline \multirow[t]{3}{*}{2} & \multirow[t]{3}{*}{ Follow TB treatment guideline to treat smear positive patients } & Always & $161(80.5 \%)$ \\
\hline & & Sometimes & $34(17 \%)$ \\
\hline & & Never & $5(2.5 \%)$ \\
\hline \multirow[t]{3}{*}{3} & \multirow[t]{3}{*}{ Opening window when TB suspected patient is in the room } & Always & 169 (84.5\%) \\
\hline & & Sometimes & $22(11 \%)$ \\
\hline & & Never & $9(4.5 \%)$ \\
\hline \multirow[t]{3}{*}{4} & \multirow[t]{3}{*}{ Using mask when approaching TB suspected patient } & Always & $124(62 \%)$ \\
\hline & & Sometimes & $51(25.5 \%)$ \\
\hline & & Never & $25(12.5 \%)$ \\
\hline \multirow[t]{3}{*}{5} & \multirow[t]{3}{*}{ Giving priority patients coughing in waiting area } & Always & $94(47 \%)$ \\
\hline & & Sometimes & $49(24.5 \%)$ \\
\hline & & Never & $57(28.5 \%)$ \\
\hline \multirow[t]{3}{*}{6} & \multirow[t]{3}{*}{ Educating TB suspected patients how to cough and sneezing. } & Always & $126(63 \%)$ \\
\hline & & Sometimes & $69(34.5 \%)$ \\
\hline & & Never & $5(2.5 \%)$ \\
\hline \multirow[t]{3}{*}{7} & \multirow[t]{3}{*}{ Proper use of fan if available } & Always & $84(42 \%)$ \\
\hline & & Sometimes & $86(43 \%)$ \\
\hline & & Never & $30(15 \%)$ \\
\hline \multirow[t]{3}{*}{8} & \multirow[t]{3}{*}{ HCW screening for TB after contact with TB patients } & Always & $96(48 \%)$ \\
\hline & & Sometimes & $75(37.5 \%)$ \\
\hline & & Never & $29(14.5 \%)$ \\
\hline \multirow[t]{3}{*}{9} & \multirow[t]{3}{*}{ Availability of designated sputum produced area for TB patients } & Always & $146(73 \%)$ \\
\hline & & Sometimes & $25(12.5 \%)$ \\
\hline & & Never & $29(14.5 \%)$ \\
\hline \multirow[t]{3}{*}{10} & \multirow[t]{3}{*}{ Use AFB as diagnostic tools for TB suspected patients } & Always & $154(77 \%)$ \\
\hline & & Sometimes & $20(10 \%)$ \\
\hline & & Never & $26(13 \%)$ \\
\hline \multirow[t]{5}{*}{11} & \multirow[t]{3}{*}{ Check if mask is airtight } & Always & $95(47.24 \%)$ \\
\hline & & Sometimes & $52(26.13 \%)$ \\
\hline & & Never & $53(26.63 \%)$ \\
\hline & \multirow[t]{2}{*}{ Overall practice } & Good & $140(70 \%)$ \\
\hline & & Poor & $60(30 \%)$ \\
\hline
\end{tabular}

HCW: healthcare worker. 
Nearly two thirds $(126,63 \%)$, of the participants educated TB suspected or confirmed patients on cough etiquette (covering of mouth while coughing, no spitting on the floor, etc.). Approximately two thirds $(124,62 \%)$ of participants use a respirator whenever they approach TB patients. Sixty $(30 \%)$ of them had poor practice toward TBIC.

\section{Discussion}

In this study, the majority of the respondents had good knowledge towards TB infection control. This finding is almost similar to the finding of the study conducted in Iraq revealed that (98.4\%) of HCWs had a 'good' score for knowledge of TB. ${ }^{21}$ This finding was higher than the study conducted in Addis Ababa where (63.9\%) concluded to had overall good knowledge from the total $582 \mathrm{HCWs}^{15}$ and a study conducted in Thailand indicated that $56 \%$ of healthcare providers were found to possess a 'good' level of knowledge of TB infection control. ${ }^{22}$ The difference could be due to sample size, the level of health institutions and the knowledge level of study participants.

This study showed that $70 \%$ of the respondents have good practice. This is slightly higher than the study conducted in Addis Ababa, Ethiopia (48.6\%), ${ }^{15}$ and the study conducted in the Berea District of Lesotho, South Africa that revealed that half (52.7\%) received a 'good' score for practice in the evaluation of occupational exposure to TB infection control among healthcare workers. ${ }^{17}$ The difference could be due to sample size, the level of health institutions, training they received and the practice level of study participants. Practice of the HCWs regarding TB infection control (30\%) was not good. This low practice might be due to low proportion of trained and experienced HCWs in respective health facilities.

Our study showed that $84.5 \%$ of the respondents knew the door and window should be open whenever a TB suspected or confirmed patient is in the room. This finding was higher than the study conducted in St. Luke's Medical Center, Philippines, where 39\% of the respondents had good practice towards TB infection control. ${ }^{23}$ The difference could be due to the sampled health facility level and methods.
The majority (80\%) knew the importance of educating TB patients to cover their mouths with a handkerchief and $86 \%$ knew the need of infection control committee. These findings are consistent with $\mathrm{WHO}$ TBs treatment guideline. ${ }^{24}$

Respiratory protection control is the third level of a TB infection control program and consists of the use of protective equipment in situations of a high risk for exposure to TB disease. ${ }^{7}$ However, this study showed that $45 \%$ of participants wrongly believed a surgical mask can protect HCWs from inhaling M. tuberculosis containing droplets. This result is nearly consistent with the finding from northwestern part of the country. ${ }^{18}$ The present study found that $78.5 \%$ of the study participants had positive attitude towards TB infection control, which was consistent with a study conducted in Nepal, in which $73.2 \%$ of healthcare providers had positive attitude towards TB infection control. ${ }^{13}$

\section{Conclusion}

Generally, the results of this study revealed that high proportion of HCWs had relatively good knowledge towards TBIC. Around $60 \%$ of HCWs wrongly believed surgical masks can protect HCWs from inhaling $M$. tuberculosis containing aerosols. Around two thirds of health professionals had relatively good practice towards TB infection control. Low proportions of the participants were trained on TB infection control. More than half of the rooms where HCWs are working had cross ventilated windows.

Training of health professionals with emphasis on practical aspects is vital to strengthen the implementation of TB infection control activities. Giving on the job training for junior staff is important to improve TB infection control practice. Using focus group discussions or in-depth interviews to find out the attitude of HCW towards TB infection control is important.

\section{Acknowledgements}

We would like to thank our study participants for their cooperation to obtain information. Then we would like extend our thanks to the Wollega University for its support and direction to investigation of this study. 


\section{Competing interest}

The authors declare that no competing of interest

\section{Funding}

The author declares that there is no fund received to carry out, and to publish this result

\section{References}

1. Global tuberculosis report 2018. Geneva: World Health Organization; 2018. Licence: CC BY-NC-SA 3.0 IGO.

2. World Health Organization. Global tuberculosis report 2013. World Health Organization 2013. https://apps.who.int/iris/ handle/10665/91355.

3. Deribew A, Deribe K, Dejene T, et al. Tuberculosis burden in Ethiopia from 1990 to 2016: Evidence from the Global Burden of Diseases 2016 Study. Ethiop J Health Sci 2018; 28(5): 519-528. doi:http://dx.doi.org/10.4314/ejhs.v28i5.2.

4. Desalegn A. Survey on the prevalence of Mycobacterium tuberculosis among the patient visiting Nekemte hospital. Int J Microbiol Res 2017; 6(5): 236-239.

5. Chekesa B, Gumi B, Chanyalew M, Zewude A, Ameni G. Prevalence of latent tuberculosis infection and associated risk factors in prison in East Wollega Zone of western Ethiopia. PLoS ONE 2020;15(5): e0233314. https://doi.org/ 10.1371/ journal.pone.0233314. https://doi.org/10.1371/journal. pone. 0233314

6. World Health Organization. Guide to Monitoring and Evaluation for Collaborative TB/HIV Activities. 2015 Revision. World Health Organization 2015.

7. Jensen PA, Lambert LA, lademarco MF, Ridzon R. Guidelines for preventing the transmission of Mycobacterium tuberculosis in health-care settings, MMWR 2005; 54(RR-17): 1-141.

8. Reyes-Guillén I, Sánchez-Pérez HJ, Cruz-Burguete J, Izaurieta-de Juan M. Anti-tuberculosis treatment defaulting. An analysis of perceptions and interactions in Chiapas, Mexico. Salud Publica Mex 2008; 50(3): 251-257. https://doi. org/10.1590/50036-36342008000300009

9. Baussano I, Nunn P, Williams B, Pivetta E, Bugiani M, Scano F. Tuberculosis among health care workers. Emerg Infect Dis 2011; 17(3): 488-494. https://doi.org/10.3201/ eid1703.100947

10. Padayatchi N, Daftary A, Moodley T, Madansein R, Ramjee A. Case series of the long-term psychosocial impact of drugresistant tuberculosis in HIV-negative medical doctors. Int J Tuberc Lung Dis 2010; 14(8): 960-966.

11. Harries AD, Hargreaves NJ, Gausi F, Kwanjana JH, Salaniponi FM. Preventing tuberculosis among health workers in Malawi. Bull World Health Organ 2002; 80(7): 526-531.

12. Zhang $\mathrm{X}$, Jia $\mathrm{H}$, Liu $\mathrm{F}$, et al. Prevalence and risk factors for latent tuberculosis infection among health care workers in China: a cross-sectional study. PLoS One 2013; 8(6): e66412. https://doi.org/10.1371/journal.pone.0066412
13. Shrestha A, Bhattarai D, Thapa B, Basel P, Wagle RR. Health care workers' knowledge, attitudes and practices on tuberculosis infection control, Nepal. BMC Infect Dis 2017; 17: 724. https://doi.org/10.1186/s12879-017-2828-4

14. Geberemariyam BS, Donka GM, Wordofa B. Assessment of knowledge and practices of healthcare workers towards infection prevention and associated factors in healthcare facilities of West Arsi District, Southeast Ethiopia: a facilitybased cross-sectional study. Arch Public Health 2018; 76(1): 69. https://doi.org/10.1186/s13690-018-0314-0

15. Gizaw GD, Alemu ZA, Kibret KT. Assessment of knowledge and practice of health workers towards tuberculosis infection control and associated factors in public health facilities of Addis Ababa, Ethiopia: A cross-sectional study. Arch Public Health 2015; 73(1): 15. https://doi.org/10.1186/s13690015-0062-3

16. Farley JE, Tudor C, Mphahlele $M$, et al. A national infection control evaluation of drug-resistant tuberculosis hospitals in South Africa. Int J Tuberc Lung Dis 2012; 16(1): 82-89. https:// doi.org/10.5588/ijtld.10.0791

17. Bhebhe LT, Van Rooyen C, Steinberg WJ. Attitudes, knowledge and practices of healthcare workers regarding occupational exposure of pulmonary tuberculosis. Afr J Prim Health Care Fam Med 2014; 6(1): E1-6.

18. Temesgen C, Demissie M. Knowledge and practice of tuberculosis infection control among health professionals in Northwest Ethiopia; 2011. BMC Health Serv Res 2014; 14: 593. https://doi.org/10.1186/s12913-014-0593-2

19. Federal Ministry of Health, Ethiopia. Guidelines for clinical and programmatic management of TB, TB/HIV and leprosy in Ethiopia, fifth edition. Addis Ababa, Ethiopia: Addis Ababa, Ethiopia, April 2012.

20. World Health Organization. WHO Guidelines on tuberculosis infection prevention and control, 2019 update. Geneva: World Health Organization 2019. https://www.who.int/ $\mathrm{tb} /$ publications/2019/guidelines-tuberculosis-infectionprevention-2019/en/

21. Hashim DS, Al Kubaisy W, Al Dulayme A. Knowledge, attitudes and practices survey among health care workers and tuberculosis patients in Iraq. East Mediterr Health J 2003; 9(4): 718-731.

22. LertkanokkunS, OkanurakK, KaewkungwalJ, Meksawasdichai N. Healthcare providers' knowledge, attitudes \& practices regarding tuberculosis care. JITMM2012 Proceedings 2013; 2: 1-10.

23. Yu CT, Zantua RR, Sto TLJH: Pulmonary tuberculosis: knowledge, attitudes and practices of selected physicians in a tertiary-care hospital. Philippines. J Microbiol Infect Dis 2002; 31(1): 1-8.

24. World Health Organization. Guidelines for treatment of drug-susceptible tuberculosis and patient care, 2017 update. Geneva: World Health Organization; 2017. Licence: CC BYNC-SA 3.0 IGO. 